\title{
Molecular physiopathogenetic mechanisms and development of new potential therapeutic strategies in persistent pulmonary hypertension of the newborn
}

\author{
Giuseppe Distefano and Pietro Sciacca*
}

\begin{abstract}
Persistent pulmonary hypertension of the newborn (PPHN) is a cyanogenic plurifactorial disorder characterized by failed postnatal drop of pulmonary vascular resistance and maintenance of right-to-left shunt across ductus arteriosus and foramen ovale typical of intrauterine life. The pathogenesis of PPHN is very complex and can result from functional (vasoconstriction) or structural (arteriolar remodeling, reduced pulmonary vessels density) anomalies of pulmonary circulation. Etiopathogenetic factors heterogeneity can strongly condition therapeutical results and prognosis of PPHN that is particularly severe in organic forms that are usually refractory to selective pulmonary vasodilator therapy with inhaled nitric oxide. This paper reports the more recent acquisitions on molecular physiopathogenetic mechanisms underlying functional and structural forms of PPHN and illustrates the bases for adoption of new potential treatment strategies for organic PPHN. These strategies aim to reverse pulmonary vascular remodeling in PPHN with arteriolar smooth muscle hypertrophy and stimulate pulmonary vascular and alveolar growth in PPHN associated with lung hypoplasia.In order to restore lung growth in this severe form of PPHN, attention is focused on the results of studies of mesenchymal stem cells and their therapeutical paracrine effects on bronchopulmonry dysplasia, a chronic neonatal lung disease characterized by arrested vascular and alveolar growth and development of pulmonary hypertension.
\end{abstract}

Keywords: Persistent neonatal pulmonary hypertension, Pulmonary vascular remodeling, Pulmonary vessels underdevelopment, Lung hypoplasia, Pulmonary vasodilative therapy, Stem cells based therapy

\section{Introduction}

Persistent pulmonary hypertension of the newborn (PPHN), first described as "persistence of fetal circulation" by Gersony and Sinclair in 1969 [1], is a cyanogenic disorder characterized by the lack of postnatal drop of pulmonary vascular resistance and by the persistence of the typical intrauterine right-to-left shunting of blood through foramen ovale and ductus arteriosus. The incidence of PPHN is between 0.43 and 6.6 newborns per 1000 live births and is most common in term and near term newborns [2-4]. Despite the major advances in treatment of newborns with cardiorespiratory diseases, PPHN is still one of the main causes of neonatal death, mortality being around 10-20\% [5]. The

\footnotetext{
* Correspondence: pietrosciacca@hotmail.it

Department of Pediatrics, Pediatric Cardiology Service, University of Catania, Via S.Sofia 78, Catania 95123, Italy
}

(c) 2015 Distefano and Sciacca; licensee BioMed Central. This is an Open Access article distributed under the terms of the

severe outcome of PPHN is probably linked to the broad spectrum of etiopathogenetic factors some of which can negatively influence therapeutical results. Recent researches on the development of PPHN have shown the important role of perinatal fetal environment (e.g. smoke and drug exposure, stress or pain, maternal obesity and diabetes, caesarean section etc.) plus the epigenetic changes that pre and postnatal stimuli can determine in the expression of genes involved in perinatal pulmonary circulation regulation [6-8].

The purpose of this article is to review the physiopatogenetic aspects of PPHN and underline the molecular mechanisms that can constitute the basis of new potential therapeutical strategies for severe forms of PPHN that are resistant to current treatment. 


\section{Regulation of perinatal pulmonary circulation}

During intrauterine life, pulmonary vascular resistance is elevated and systemic resistance low, fetal channels (ductus arteriosus and foramen ovale) are patent with right-to-left shunt and both ventricles work in parallel instead of in series.

Elevated fetal pulmonary vascular resistance is partly caused by pulmonary collapse and vessels tortuosity but above all by pulmonary arterioles vasoconstriction. Normally these arterioles present a muscular medial tunic up to the preacinar zones then disappearing in intraacinar branches [9]. In physiological conditions the periarteriolar muscular layer develops mainly during the last months of gestation and thus is not well represented in preterms [10]. A thicker muscle layer results in a narrower lumen and reduced arterioles compliance, and this may play a role in increased vascular pulmonary resistance, regardless of vasoconstriction [10]. Relative hypoxia in the blood perfusing the fetal lung plays an important role in pulmonary arteriolar vasoconstriction. Pulmonary arteriolar muscle fibers are very sensitive to oxygen tension and $\mathrm{pH}$ variations and they contract in conditions of hypoxia and acidosis and relax when $\mathrm{PaO} 2$ and $\mathrm{pH}$ increase [11]. Pulmonary arteriolar tone can also be influenced by several humoral factors present in the perinatal circulation. Some of these (thromboxane, endothelin etc.) possess a vasoconstricting action, whereas others (prostacyclin, nitric oxide, etc.) determine vasodilatation $[12,13]$.

At birth systemic resistance rises rapidly. On the contrary, when breathing starts pulmonary resistance falls after lung and pulmonary vascular bed expansion and, in particular, following arteriolar dilatation caused by the rapid increase of arterial oxygen tension. Oxygen can act directly on myocytes, but its action is mainly mediated by humoral factors (specially prostacyclin and nitric oxide) secreted by the pulmonary arteriolar endothelium, a tissue that performs a key function in perinatal pulmonary circulation regulation $[10,12,14,15]$. Secretion of these vasodilating agents can also be induced by mechanical stimuli such as ventilation and shear stress caused by vascular bed distension and abrupt increment of pulmonary blood flow [5].

Nitric oxide (NO) is produced by endothelial NO synthase (eNOS) using L-arginine as substrate and producing L-citrulline as a by-product. L-citrulline in turn can be reconverted in L-arginine through a recycling pathway that is the principal source of L-arginine available to eNOS [16]. eNOS is activated by the sudden increase in postnatal oxygen tension [3]. NO determines pulmonary vasodilatation via soluble guanylate cyclase stimulation and the ensuing increase of cyclic guanylate monophosphate (cGMP) concentrations in vessel smooth muscle cells [17]. cGMP endomyocytic levels are regulated by phosphodiesterase 5 (PDE5), a kinase enzyme abundantly expressed in pulmonary tissue during fetal life and able to hydrolyze
cGMP [18]. Pulmonary arterioles vasodilatation at birth is inversely correlated to the thickness that their muscular tunic reaches at the end of gestation. Histological observations $[19,20,12]$ revealed that the muscular tunic is progressively reabsorbed during the postnatal period (Figures 1, 2, 3 and 4). This process is sustained by apoptotic events involving pulmonary vessel myocytes and is generally completed within the first two weeks of life. However, sometimes it may take some days longer and thus impact negatively on postnatal circulation adjustments as the muscular tunic thickness narrows the lumen and makes the pulmonary arterioles more reactive to vasoconstricting stimuli $[21,22]$.

\section{Physiopathology of PPHN}

The fundamental physiopatological feature of this syndrome is the failure of the postnatal drop in pulmonary vascular resistance, and the presence of elevated pressure values in the pulmonary artery and right sections of the heart [7]. This maintains the typical fetal intrauterine right-to-left shunt in the ductus and foramen ovale resulting in cyanosis and severe hypoxemia refractory to oxygen therapy. Hypoxemia and the ensuing metabolic acidosis determine in turn arteriolar vasoconstriction, leading to a further increase in pulmonary vascular resistance, and if this vicious circle is not rapidly eradicated by adequate treatment the negative clinical and hemodynamic situation tends to worsen producing a progressive cardiac dysfunction with fatal outcome (Figure 5).

\section{Pathogenesis of PPHN}

Pathogenetically there are two forms of PPHN: one functional where elevated vascular pulmonary resistance is only due to pulmonary arteriolar vasoconstriction, and the other organic where vasoconstriction is of secondary importance and increased resistance is mainly caused by

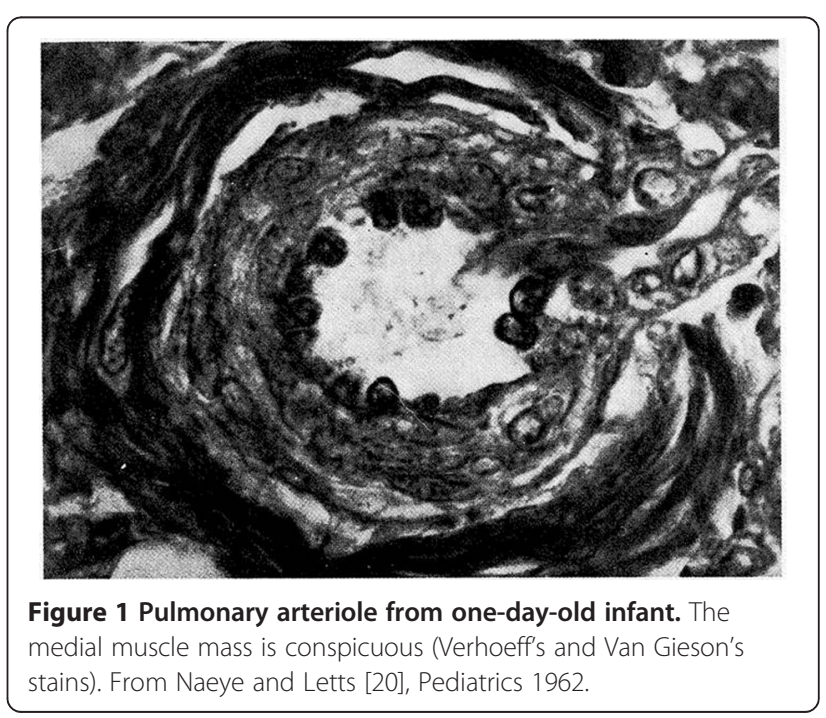




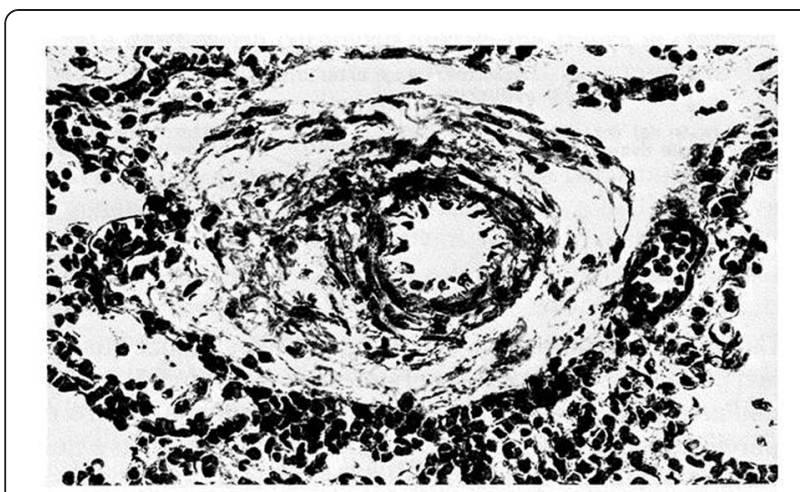

Figure 2 Pulmonary arteriole from a polymalformed non hypoxemic term infant who died at 6 days of life. Medial muscle mass is still evident (H.E. stains). From Distefano G et al. [12], Med Surg Ped 1992. (Personal observation).

substantial structural changes in the pulmonary circulation. These changes are generally represented by pulmonary arterioles lumen narrowing caused by muscular tunic hypertrophy and extension of smooth muscle to the intraacinar branches (normally without muscle fibers), or by poor pulmonary vessels development that reduces the size of the pulmonary vascular bed and thus increases blood flow resistance. Organic forms of PPHN include rare, and almost always fatal, cases of alveolar capillary dysplasia caused by diffuse misalignment of the arteriolar capillary venous axis that compromises respiratory exchange [23]. Both functional and organic forms of PPHN can be primary or secondary and have diverse causes [24].

\section{Functional PPHN}

Postnatal persistence of fetal pulmonary vasoconstriction Functional PPHN can be idiopathic or, more

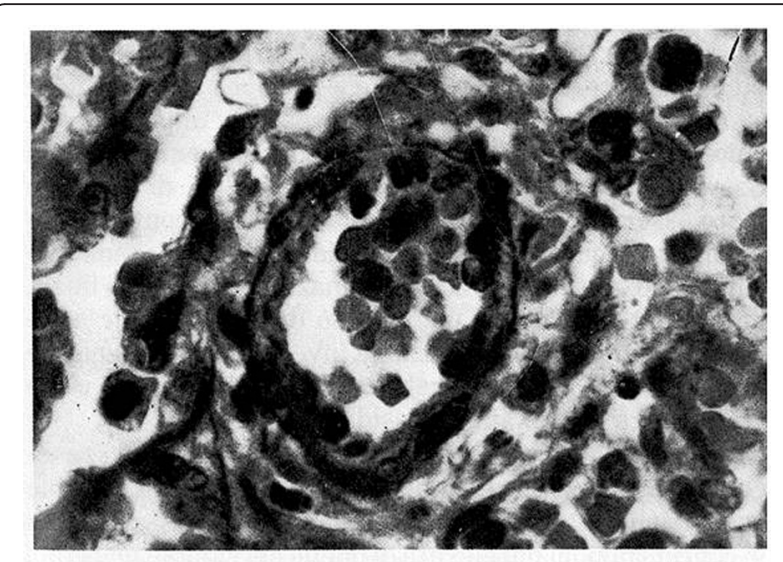

Figure 3 Pulmonary arteriole from a 4-week-old non hypoxemic infant. The relative medial muscle mass has decreased since birth (Verhoeff's and Van Gieson's stains). From Naeye and Letts [20], Pediatrics 1992

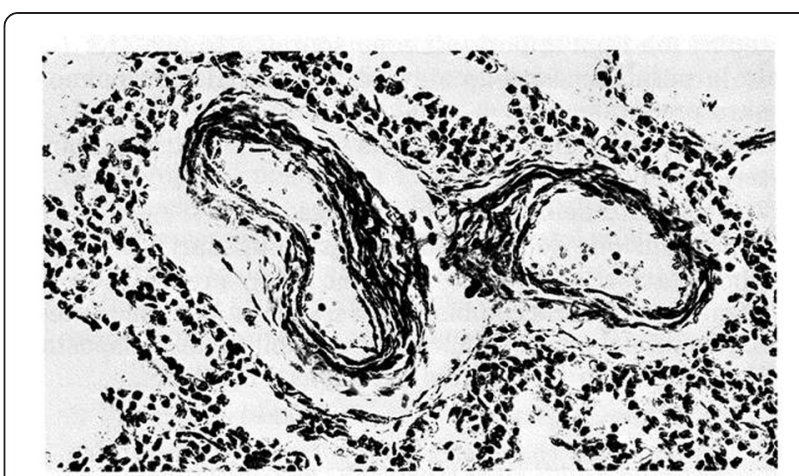

Figure 4 Pulmonary arterioles from a 22-day-old infant who died from bilateral kidney malformation. Marked thinning of medial muscle mass is evident (PAS-Gieson stains). From Distefano G et al. [12], Med Surg Ped 1992. (Personal observation).

frequently, secondary to various pathologies. In the idiopathic form, postnatal persistence of fetal pulmonary vasoconstriction is considered the expression of constitutional and/or genetic factors enhancing sensibility of pulmonary arterioles to vasoconstrictive stimuli or impairing mechanisms of NO release and action [25-27]. Reently some PPHN patients have shown variants in the genes of corticotrophin-releasing hormone receptor 1 and of its binding protein (CRHR1 and CRHBP genes). This determines reduced expression of "Peroxisome proliferatoractivated receptor-gamma (PPAR- $\gamma$ )", a transcription factor that plays an important role in myocytes proliferation and pulmonary arteriolar tone regulation [28-30]. In the secondary form, the majority of cases are due to perinatal asphyxia, present in $80-90 \%$ of the subjects, and septic processes caused by group B streptococcus, e.g. pneumonia $[1,2]$. Asphyxia and sepsis can determine pulmonary arteriolar vasoconstriction, either directly through hypoxia and acidosis or indirectly via release of vasoactive substances, such as leukotrienes, endothelin, free radicals, thromboxane, etc. [31-33] (Figure 6). Thromboxane seems to play a major role in sepsis. In experimentally induced streptococcal infections it was observed that cycloxygenase inhibitors, such as indomethacin, can prevent pulmonary hypertension [34]. Recent studies have revealed that vasoconstriction can also be determined by some phospholipids (in particular, phosphatidyl-glycerol and cardiolipin) present in the bacterial wall of streptococcus B [35]. Studies on perinatal asphyxia have focused on leukotrienes [36] and, especially, on endothelin whose plasma concentrations were markedly higher than observed in normal controls [37]. Reactive oxygen species (ROS), derived from metabolism of hypoxanthine, play a concomitant role in asphyxia [31]. In effect, oxidative stress seems able to enhance signals promoting endothelin production and reducing nitric oxide synthase (NOS) expression [38]. Moreover, recent studies reported that ROS pulmonary vasoconstrictive action can 


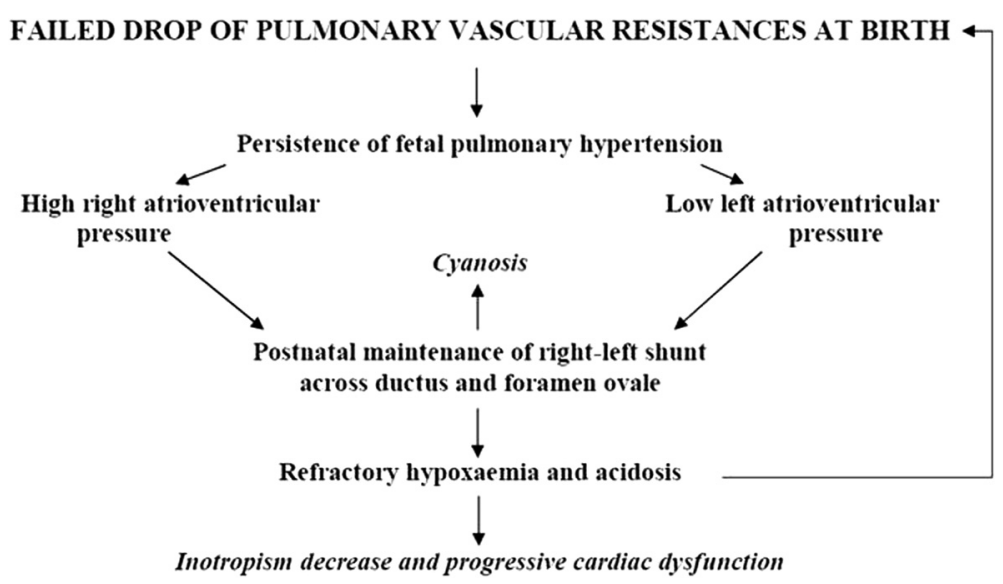

Figure 5 Physiopathology of PPHN. Vicious circle leading to progressive cardiac dysfunction.

also be mediated by isoprostanes [39]. In perinatal asphyxia, hypoxemia not only contracts pulmonary arterioles but, if prolonged, is also able to hinder muscular tunic reabsorption promoting its hypertrophy as observed in histopathological studies [20,12], (Figures 7 and 8). Similar morphological observations have been reported also in animals with induced postnatal hypoxemia [40]. Among the pulmonary parenchymal diseases associated with perinatal asphyxia - such as meconium aspiration syndrome (MAS), respiratory distress syndrome (RDS) and pneumonia (PM) - the most frequent observed in newborns with PPHN is MAS where endothelin (principally) and urotensin play an important role as powerful pulmonary vasoconstrictive agents $[41,42]$.

\section{Organic PPHN}

Hypertrophy of pulmonary arteriolar muscular tunic The first descriptions of such structural anomaly were reported many years ago in histopathological studies on newborns who died from PPHN and were not affected by neonatal asphyxia or other intercurrent pathologies $[43,21,22]$. Increased muscular tunic thickness reduces lumen caliber, leading to marked narrowing of the pulmonary arterioles and consequent obstructive type blood flow resistance. As etiology is uncertain, these forms of organic PPHN have been labeled as idiopathic [43]. Some authors believe that genetics may influence these forms of PPHN causing a primitive increased thickness of the muscular tunic of pulmonary arterioles [44]. Other studies have revealed that muscular tunic hypertrophy can be secondary to pathological events occurring during gestation and be observed, for example, in newborns subjected to accentuated chronic intrauterine hypoxia or increase of fetal pulmonary arterial pressure (Figure 9). The first event occurs during intrauterine conditions accompanied by chronic placental insufficiency and can explain the findings of the aforementioned vascular changes in small for date newborns [12] (Figure 10). The second event can occur in cases of

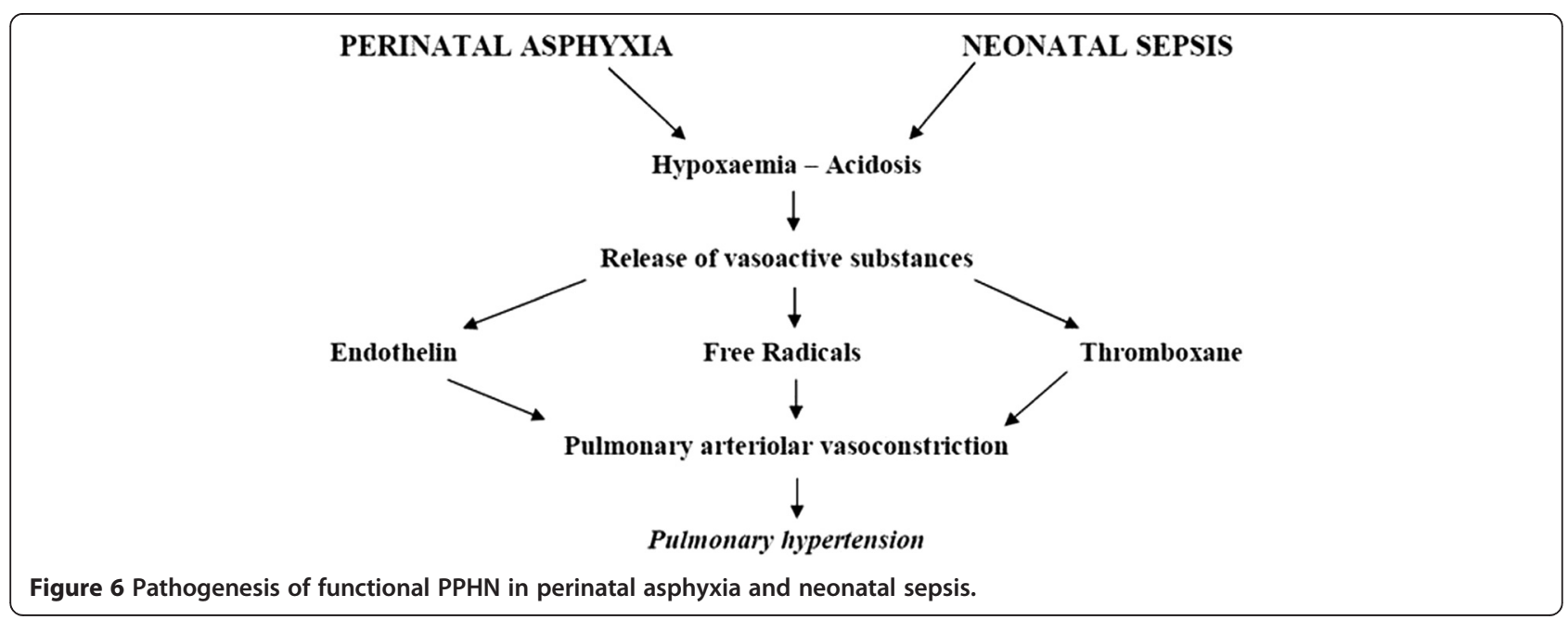




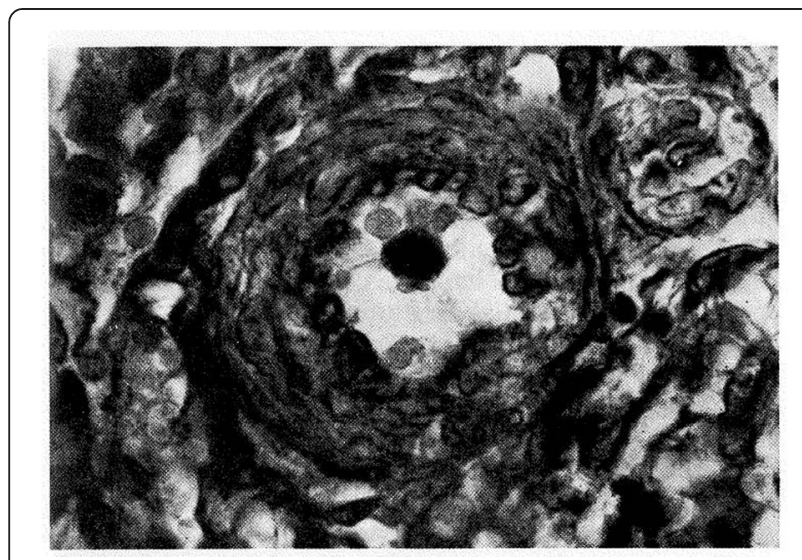

Figure 7 Pulmonary arteriole from a 6-week-old hypoxemic infant. The relative medial muscle mass present at birth has been retained (Verhoeff's and Van Gieson's stains). From Naeye and Letts [20], Pediatrics 1962.

closure in utero of Botallo's duct that can occur in newborns of pregnant women treated with prostaglandin synthetase inhibitors (indomethacin, salicylates, lithium etc.) [45] (Figure 9). The important role of chronic hypoxemia and of fetal pulmonary arterial pressure increment in determining smooth muscle hypertrophy in pulmonary arterioles has been demonstrated in experimental models of PPHN reproduced in lamb fetuses $[46,47]$. Molecular studies revealed that these two factors act on the pulmonary endothelium and can inhibit the release of $\mathrm{NO}$ and stimulate that of endothelin and of smooth muscle mitogens inducing pulmonary vessels myocytes hypertrophy $[48,49,4,6]$. PDE5, an enzyme that degrades cGMP and jeopardizes the pulmonary vasodilating effect of $\mathrm{NO}$, was markedly increased in lamb fetuses with chronic pulmonary hypertension induced by ductus ligation. Recent researchs have shown that the afore-mentioned structural changes in fetal pulmonary

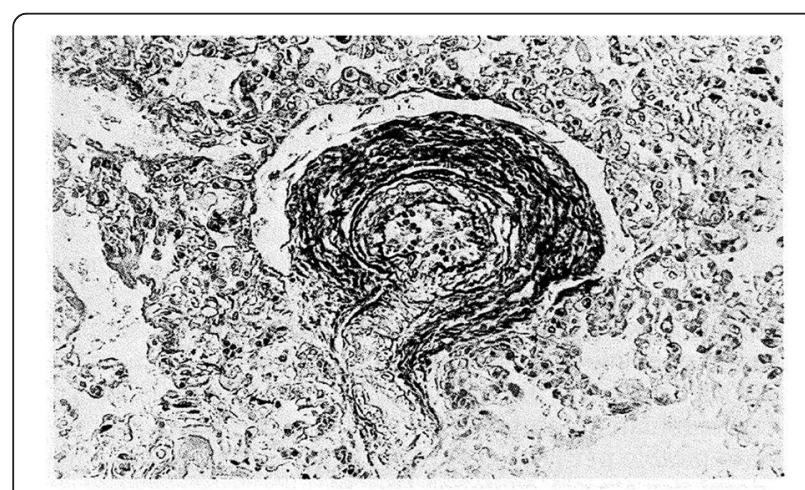

Figure 8 Pulmonary arteriole from a 11-day-old infant who died from severe perinatal asphyxia. Marked thickening of medial muscle mass is evident (PAS-Gieson stains). From Distefano G et al. [12] Med Surg Ped 1992. (Personal observation). arterioles can also occur when there is chronic use of selective serotonin reuptake inhibitors (antidepressant drugs) during pregnancy [50,51]. In effect, serotonin is a powerful pulmonary vasoconstrictor that stimulates smooth muscle cell growth and proliferation [50].

Underdevelopment of pulmonary vascular bed In this form of PPHN the failed postnatal drop of pulmonary resistance is due to diminished number of pulmonary vessels that, decreasing the cross-sectional area of pulmonary vascular bed, causes a restrictive type enhancement of resistance to pulmonary blood flow. This severe hemodynamic situation is typical of pulmonary hypoplasia, a condition often associated with congenital diaphragmatic hernia $(\mathrm{CDH})$ [9]. Indeed, it has been clearly documented that normal pulmonary vessel development is crucial for pulmonary alveoli growth and is regulated by various biochemical factors, in particular vascular endothelial growth factor (VEGF), a potent vascular cell mitogen and modulator of angiogenesis [52,53]. Studies on lamb fetuses demonstrated that inhibition of VEGF receptors impairs vascular growth and provokes pulmonary hypertension [54]. Impairment of alveolarization and vascular growth associated with reduced VEGF expression has been reported also in animals with chronic intrauterine pulmonary hypertension induced by ductus ligation [55]. The hypoplastic $\mathrm{CDH}$ lung, in addition to reduced vessels density, presents increased vascular reactivity to vasoconstricting stimuli associated with reduced nitric oxide synthase (NOS) expression and elevated endothelin production $[23,56,57,6]$.

\section{Current medical treatment of PPHN}

PPHN treatment is influenced by the multiplicity of etiopathogenic factors, the severity of pulmonary hypertension and by heart and lung function alterations. It includes a general therapy aimed at stabilizing the newborns' clinical conditions, and a more important specific treatment with pulmonary vasodilators aimed at eliminating the right-to-left shunt causing severe hypoxemia $[2,3,7,12,58]$. If such treatment fails, extracorporeal membrane oxygenation (ECMO) is required [59]. General therapy,that has been well codified for several years [12,7], and ECMO will not be addressed in this paper.

\section{Pulmonary vasodilator therapy}

Pulmonary vasodilators are essential in the treatment of PPHN to achieve the reversal of the right-to-left shunt causing hypoxemia and cyanosis.

The advent of nitric oxide (NO) therapy represented a turning-point in the treatment of PPHN. Many clinical and experimental studies have shown that inhaled nitric oxide (iNO), unlike other vasodilators (tolazoline, magnesium sulfate etc.) acting also on the systemic circle 


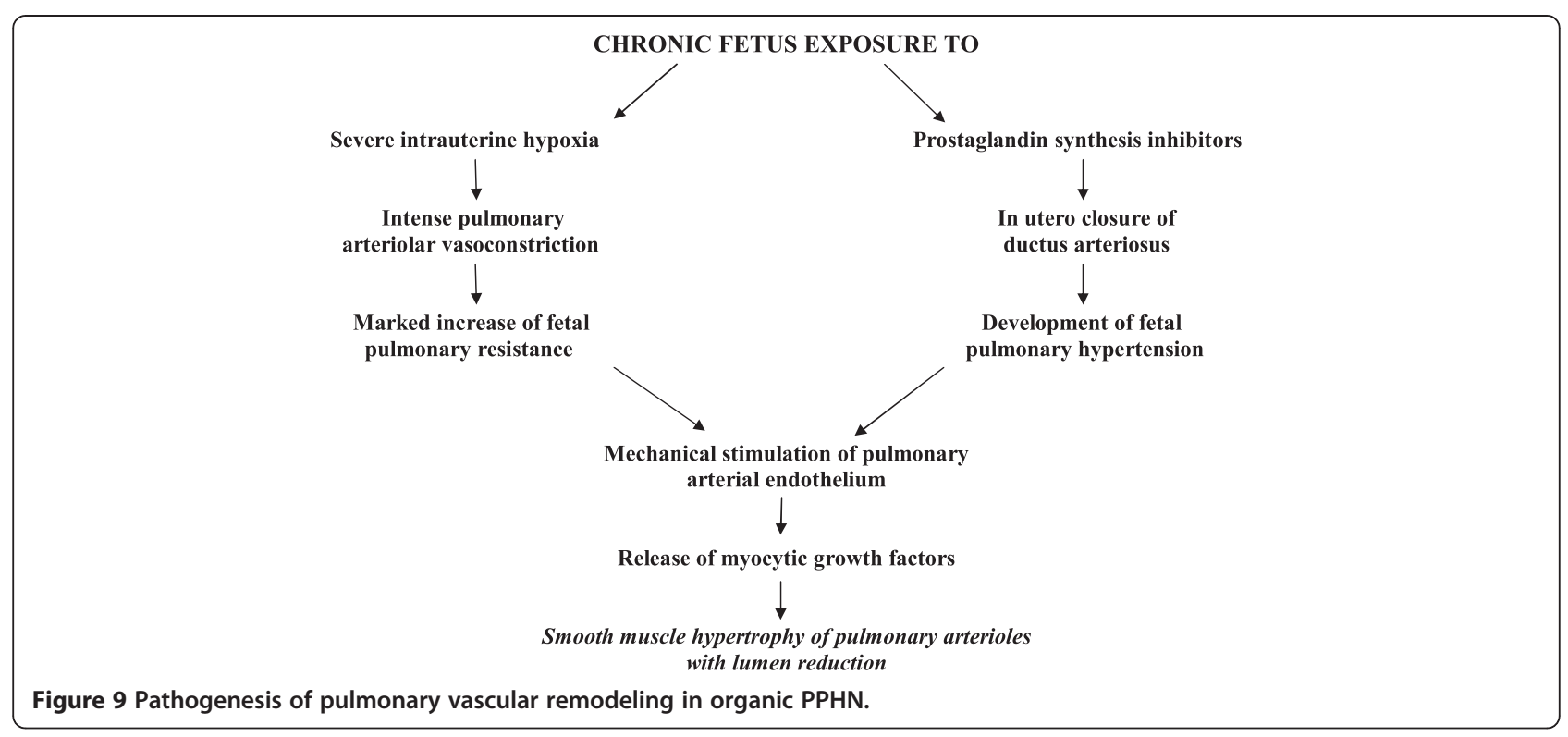

$[60,3]$, carries out a selective vasodilating action on pulmonary arterial circulation and eliminates pulmonary hypertension related hypoxemia [61-63]. iNO spreads through the alveolar epithelium to smooth muscle of the underlying vessels and dilates the pulmonary arterioles, while the part that reaches the vessel lumen, through which it could enter the peripheral circulation and cause systemic hypotension, is rapidly inactivated by combination with hemoglobin and formation of methaemoglobin [63]. In PPHN, iNO rapidly improves the oxygenation status and reduces the need for ECMO [64,65,63,2]. In a recent randomized comparative study Gonzalez et al. [66], showed that the best results with iNO were obtained when therapy was administered early on. Nevertheless clinical experience has demonstrated that iNO therapy is effective only in $50-60 \%$ of PPHN patients [67,2]. In all likelihood, this depends on the pathogenesis with optimal response to

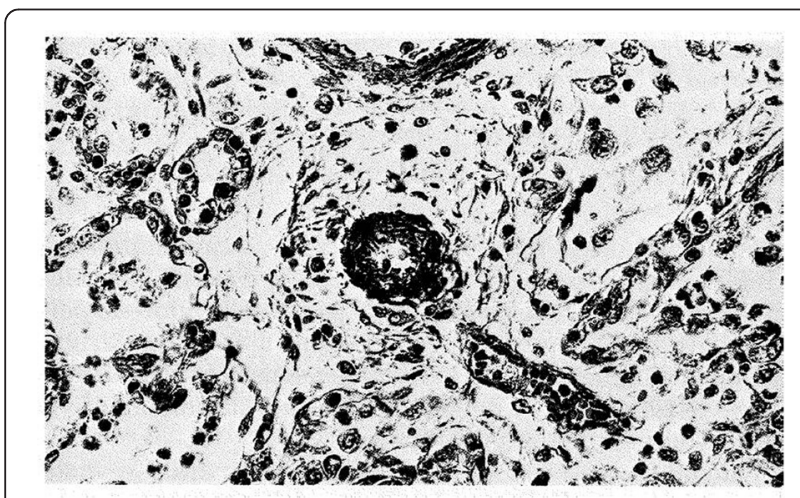

Figure 10 Pulmonary arteriole from a small for date newborn who died at 2 days of life from esophageal atresia. Marked thickening of medial muscle mass is evident (H.E. stains). From Distefano G et al. [12], Med Surg Ped 1992. (Personal observation). treatment in functional PPHN, that is induced only by pulmonary arteriolar vasoconstriction, and partial or absent response in organic PPHN where structural alterations of pulmonary arterioles sustain stable pulmonary vascular resistance.

PPHN refractory to INO can also be linked to disruptions in the complex down stream signaling pathways activated by the same $\mathrm{NO}$ and negatively interfering with its action on vascular myocytes. These changes are sometimes induced by epigenetic alterations and include various anomalies, such as reduced response of guanylate cyclase to $\mathrm{NO}$, reduced expression or activity of guanylate cyclase, increased clearance of cGMP by phosphodiesterase [68]. In cases of resistant PPHN to INO therapy, an alternative treatment could be the use of PDE inhibitors that preventing cGMP degradation and raising its intramyocytic concentration, promote pulmonary arterioles vasodilation [63,2]. One of these substances, the powerful PDE5 inhibitor sildenafil, has attracted most attention. PDE5 is the most expressed isoform in the lung during the perinatal period and its activity is increased in PPHN animal models [7]. Oral or intravenous administration of sildenafil is able to lower pulmonary vascular resistance with poor impact on systemic resistance in experimental and clinical studies [69-71]. Some studies revealed its efficacy also in cases of PPHN associated with congenital diaphragmatic hernia where it can improve pulmonary vascular function and promote pulmonary growth [72]. Furthermore it has been reported that this drug enhances vasodilative response to endogenous nitric oxide and thus prevents pulmonary hypertension rebound after the suspension of nitric oxide therapy [70]. Adenosine, an eNOS agonist, could increase the formation of $\mathrm{NO}$ and because of its 
extremely short half-life, it may have fewer systemic side effects. However, the experience using this substance in PPHN is still very limited [3]. Additional pulmonary vasodilatory effect in cases of PPHN not responding well to INO therapy has been reported using inhaled prostacyclin (PGI2) and intravenous infusion of milrinone. These substances trigger off complementary effects on pulmonary vascular myocytes to those obtained by $\mathrm{NO}$ as they raise cAMP intracellular concentrations. PGI2 directly stimulates adenil cyclase, while milrinone acts indirectly by inhibiting PDE3, a cAMP hydrolyzing enzyme. However, to date controlled studies confirming their efficacy are lacking [63,3]. A recent randomized, double-blind, placebo-controlled, prospective study in 47 newborns infants with PPHN showed that Bosentan, an endothelin-1 antagonist, is an efficacious pulmonary vasodilator [73].

Despite progress in PPHN therapy, this syndrome has still a severe prognosis. Clearly, the major problems involve newborns presenting structural changes in pulmonary circulation, such as muscle hypertrophy and pulmonary vascular bed hypoplasia that reduce the efficacy of vasodilator therapy also when it acts selectively on pulmonary vessels. Advances in molecular pathogenetic studies seem to offer new potential therapeutic solutions for these severe cases of PPHN.

\section{New potential therapeutical strategies}

Increasing knowledge of complex molecular mechanisms involved in the muscularization process of pulmonary arterioles and the development of pulmonary vascular bed, forms the basis for new therapeutic strategies aimed at promoting periarteriolar muscle involution in PPHN associated with pulmonary vascular remodeling, and at stimulating angiogenic processes in PPHN associated with underdevelopment of pulmonary vasculature.

A major role in pulmonary vascular remodeling seems to be played by endothelin-1 (ET-1) whose concentrations are increased in newborns with PPHN. ET-1 not only has a well known vasoconstrictive action, but also stimulates proliferation of pulmonary arterial smooth muscle cells (PASMCs), as observed by Wedgwood et al. [74] in in vitro studies on PASMCs isolated from lamb fetuses. These effects are linked to ETa receptors activation in the PASMCs; in fact blockade of these receptors attenuated fetal pulmonary hypertension and inhibited pulmonary periarteriolar musculature hypertrophy in ovine models where PPHN was induced by ductal ligation [74]. Furthermore, these authors observed that the mitogenic effect on PASMCs linked to ETa receptors stimulation was mediated by NADPH oxidase through increased production of superoxide, that in turn stimulate activation of mitogen-activated protein(MAP) kinases, and can be prevented by antioxidant treatment and by NADPH oxidase inhibition [75] (Figure 11). In further studies on lamb fetuses the same authors [76] reported that PASMACs proliferation induced by ET-1 via the superoxide can be inhibited by both endogenous and exogenous NO. Using the NO donor spermine NONOate they observed that nitric oxide released by this substance, reacting with superoxide to form peroxynitrite, lowers superoxide levels preventing its stimulating effect on PASMCs proliferation and viability and can also determine apoptosis of the same PASMCs through the activation of pro-apoptotic caspases enzymes [76]. Increased superoxide production in pulmonary arteries and elevated ET-1 concentrations associated with reduced NO production have been found in lambs with chronic ductal ligation-induced PPHN $[77,78]$.

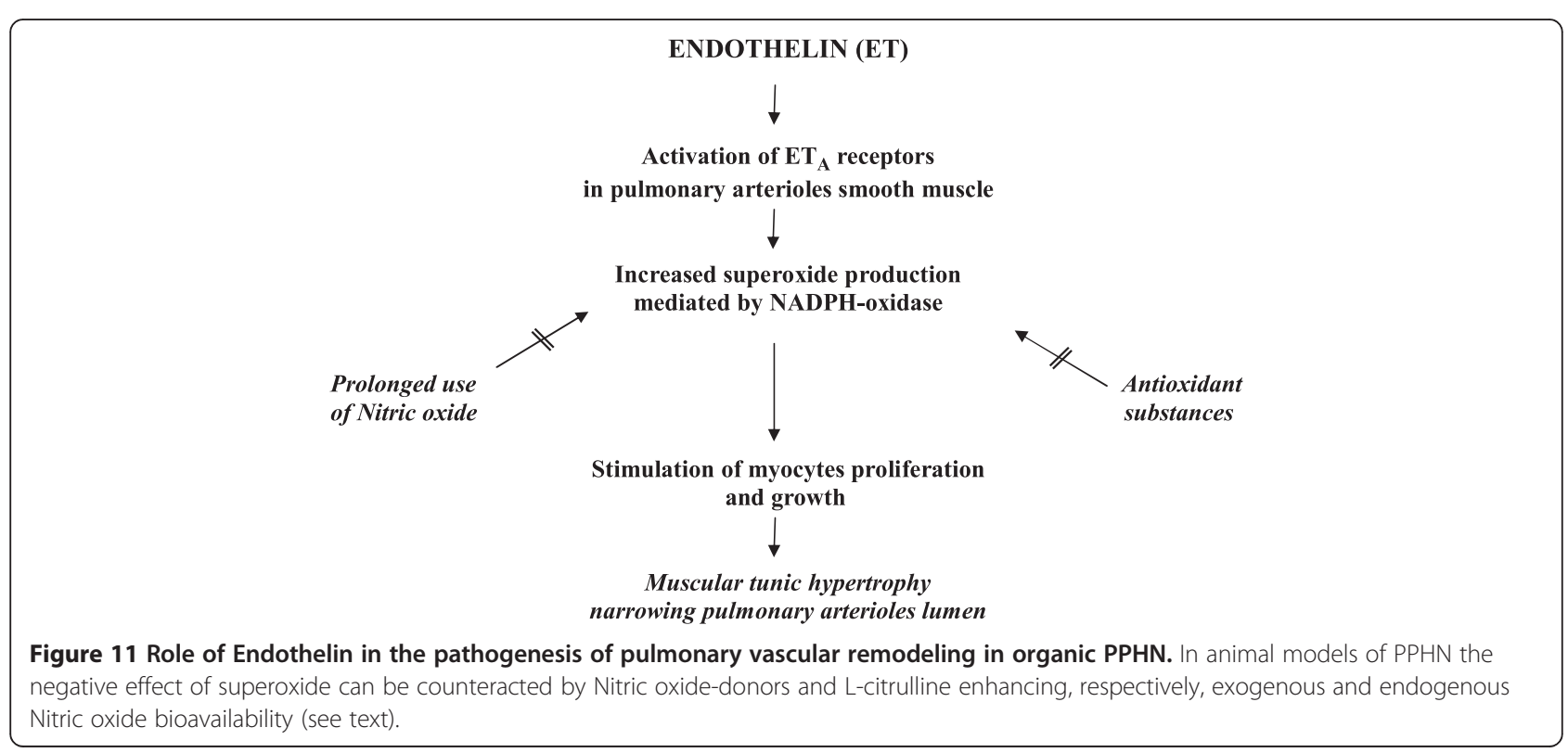


Such experimental data indicate that prolonged administration of NO, also through use of NO donors, combined with antioxidant therapy could be a useful therapeutic tool to reverse smooth muscle hypertrophy in severe forms of PPHN associated with pulmonary vascular remodeling. In order to increase NO availability, some authors have taken into consideration therapeutical use of L-citrulline. This substance in fact, is capable of enhancing endogenous nitric oxide production via its action that improves pulmonary eNOS function [16]. Recently a study in newborn piglets exposed to 10 days of chronic hypoxia showed that pulmonary hypertension development can be prevented by supplementation of L-citrulline [79]. In children undergoing cardiopulmonary bypass for cardiosurgery it has been observed that L-citrulline supplementation was able to prevent postoperative pulmonary hypertension [80]. If these results are confirmed by a larger series of studies, the use of L-citrullin could be a useful remedy for preventing the development of pulmonary hypertension and vascular remodeling in neonates affected by pathologies associated with prolonged hypoxia.

Regarding PPHN with reduced pulmonary vascular bed it is known that the syndrome is typical of the pathological conditions associated with pulmonary hypoplasia, in particular congenital diaphragmatic hernia (CDH) [9]. Reduced pulmonary vessel density has also been observed in clinical and experimental forms of PPHN secondary to chronic intrauterine fetal pulmonary hypertension [55,7].

Following embryonic vasculogenesis where primordial vascular structures are formed, pulmonary circulatory network development is induced by angiogenesis a biological process regulated by a series of transcription and growth factors, in particular VEGF that is paramount in pulmonary vessel growth [13]. In the human fetal lung, VEGF is expressed in epithelial cells and myocytes while its receptors are located in endothelial cells closely apposed to the developing epithelium [81]. VEGF's angiogenic effect on pulmonary endothelium is mediated by $\mathrm{NO}$ produced by the activation of endothelial nitric oxide synthase (eNOS) [82]. Reduced VEGF expression with impaired nitric oxide signals has been reported in experimental PPHN models associated with chronic fetal pulmonary hypertension after in utero ductal ligation, and with nitrofen-induced diaphragmatic hernia. Both these conditions present vascular remodeling and reduced pulmonary vessel density $[54,83]$. NO administered to rats with nitrofen-induced $\mathrm{CDH}$ to stimulate angiogenesis enhanced lung growth [13]. The results of this research suggest that cases of PPHN associated with reduced pulmonary vessels development could benefit from prolonged treatment with iNO or with $\mathrm{NO}$ donors. Benefits would be two-fold as such therapy could determine the regression of periarteriolar muscular hypertrophy, and also stimulate pulmonary angiogenesis. On the other hand, reduced eNOS expression with low blood levels of NO has been reported in human newborns with diaphragmatic hernia [56] and in experimental animal models with PPHN associated with chronic hypoxia and pulmonary hypertension [84,85]. Recently Teng et al. performed in vitro studies on pulmonary artery endothelial cells (PAEC) isolated from lambs with intrauterine ductal ligation-induced PPHN and showed that angiogenesis can be strongly stimulated by sepiapterin, a substance capable of increasing intracellular levels of tetrahydrobiopterin (BH4) that are low in these cells. BH4 is a cofactor of critical importance to maintain active eNOS catalytic function for NO production, and in PAEC of these PPHN lambs can be inactivated by its oxidation in dihydrobiopterin (BH2), due to increased peroxynitrite formation in these cells [86]. Moreover, in their previous study using the same PPHN lamb model, Teng et al. [87] showed that impaired angiogenesis in PAEC improved after addition of antioxidants on tissue culture media. The results of such researches suggest that the use of sepiapterin to increase PAEC BH4 intracellular levels might be a potentially useful therapy for improving eNOS function and restoring angiogenesis in PPHN cases with reduced density of pulmonary vessels. Furthermore, the effectiveness of this treatment could be potentiated by combining sepiapterin supplementation and antioxidant therapy.

\section{Future perspectives in PPHN with lung hypoplasia}

In this field, very interesting therapeutical perspectives are emerging from experimental studies on bronchopulmonary dysplasia (BPD), a chronic neonatal lung disease characterized by arrested vascular and alveolar growth and development of pulmonary hypertension. They indicate the potential use of mesenchymal stem cells (MSCs) or endothelial progenitors cells (EPCs) for restoring vascular and alveolar growth $[88,89]$. MSCs are multipotent cells capable of self-renewal and differentiating into various cell types, including parenchymal and vascular pulmonary cells, and can be obtained from bone marrow (BM), umbilical cord blood (UCB) and adipose tissue [89]. EPCs are BM or UCB-derived vascular precursor cells which can be circulating and also resident within vessels wall. Recently several studies In various animal models of BPD have demonstrated that intravenous or intratracheal delivery of bone marrow-derived MSCs (BMSCs) was capable of regenerating lung vascular and alveolar growth and reversing associated pulmonary hypertension [90]. The same effects in BPD models have been obtained with human UCB-derived EPCs [91]. However, a very important acquisition emerging from stem cells studies is that, rather than cells replacement, the beneficial therapeutic effect of BM and UCB-derived MSCs or EPCs can be mediated through a paracrine 
mechanism [92]. This possibility is suggested by low intrapulmonary engraftment rates of these transplanted cells and supported by in vitro and in vivo studies showing that cell-free conditioned media, derived from cultures of these cells, prevent and/or restore arrested alveolar and vascular growth in neonatal rodents models of lung injury induced by chronic hyperoxia [92]. MSCsderived conditioned media are rich in soluble factors such as VEGF, stanniocalcin-1 (a potent antioxidant) and specially exosomes, microvesicles containing microRNAs molecules and other bioactive molecules involved, respectively, in gene expression regulation, intercellular communication signals and the control of inflammatory response. These factors can protect the lung from injuries inducing alveolar and vascular damage and stimulate proliferation and differentiation of resident epithelial and endothelial progenitors cells and restore pulmonary growth $[92,93]$. Recently, the therapeutical importance of exosomes has been demonstrated by Lee et al. [94] in the rodent model of chronic hypoxia-induced pulmonary hypertension. In this model the intravenous delivery of both animal or human MSC-derived exosomes inhibited vascular remodeling and development of pulmonary hypertension; on the contrary, no therapeutical effect was obtained by removing exosomes from MSCs-conditioned media.

\section{Conclusions}

PPHN is a plurifactorial syndrome with a complex pathogenesis sustained by functional (vasoconstriction) or structural (periarteriolar muscular hypertrophy, reduced pulmonary vessels density) pulmonary circulation anomalies. Despite considerable therapeutical progress achieved using inhaled nitric oxide (INO), a selective pulmonary vasodilator, PPHN still remains a major cause of mortality in all neonatal centers. Prognosis is particularly severe in organic forms, that are refractory to INO and other alternative pulmonary vasodilators such as sildenafil and prostacyclin. Recent advances, in the understanding of molecular physiopathogenetic mechanisms, have paved the way for new potential therapeutical strategies for these organic forms that, as observed in animal models, could benefit from prolonged use of nitric oxide donors (NO-donors) and of L-citrulline and sepiapterin. These substances are capable of increasing, respectively, the exogenous and endogenous availability of NO. In PPHN with pulmonary vascular remodeling, increased circulatory levels of NO can reverse periarteriolar muscular hypertrophy counteracting the stimulating effect of endothelin-1 (whose concentrations are elevated in these cases) on pulmonary myocites proliferation and growth. While in PPHN with reduced density of pulmonary vessels, high NO levels can stimulate vascular growth mediating angiogenic effect of VEGF on pulmonary endothelial cells.
Nevertheless, regarding more severe PPHN associated with lung hypoplasia (as in congenital diaphragmatic hernia), very fascinating future therapeutical perspectives are emerging from experimental studies on bronchopulmonary dysplasia (BPD). Such indicate the possible use of human umbilical cord blood-derived mesenchymal stem cells (UCB-derived MSCs) and/or of bioactive factors obtained by their cultures to restore vascular and alveolar growth and reverse pulmonary hypertension. Recently, it has been shown that some of these factors (exosomes) are, also, effective in inhibiting vascular remodeling and pulmonary hypertension development in rodents models of hypoxia-induced PPHN. If the beneficial results achieved in experimental models are confirmed by further controlled studies and reproduced in human newborns, it is reasonable to postulate that, in near future, the use of bioactive substances obtained by cultures of human UCB-derived MSCs (easily accessible at birth) could revolutionize the prognosis of severe organic PPHN.

\section{Competing interests}

The authors declare that they have no competing interests.

\section{Authors' contributions}

GD conceived and designed the study. PS wrote the paragraphs "Regulation of perinatal pulmonary circulation", Physiopathology of PPHN and "Pathogenesis of functional PPHN". Both authors read and approved the final manuscript.

Received: 8 April 2014 Accepted: 13 January 2015

Published online: 08 February 2015

\section{References}

1. Gersony WM, Duc GV, Sinclair JC. "PCF" syndrome (persistence of the fetal circulation). Circulation. 1969;40(SupplIII):87.

2. Stayer SA, Liu Y. Pulmonary hypertension of the newborn. Best Pract Res Clin Anesthesiol. 2010;24:375-86.

3. Teng R-J, Wu T-J. Persistent pulmonary hypertension of the newborn. J Formosan Med Assoc. 2013;112:177-84.

4. Roofthooft MTR, Elema A, Bergman KA, Berger RMF. Patient characteristics in persistent pulmonary hypertension of the newborn. Pulmon Med. 2011;2011:858154. doi:10.1155/2011/858154.

5. Abman $\mathrm{SH}$. Recent advances in the pathogenesis and treatment of persistent pulmonary hypertension of the newborn. Neonatology. 2007;91:283-90.

6. Delaney C, Cornfield DN. Risk factors for persistent pulmonary hypertension of the newborn. Pulmon Circul. 2012;2:15-20.

7. Storme L, Aubry E, Rakza T, Houeijeh A, Debarge V, Tourneux P, et al. Pathophysiology of persistent pulmonary hypertension of the newborn: impact of the perinatal environment. Arch Cardiovasc Dis. 2013;106:169-77.

8. Xu X-F, Ma X-L, Shen Z, Wu X-L, Cheng F, Du L-Z. Epigenetic regulation of the endothelial nitric oxide synthase gene in persistent pulmonary hypertension of the newborn rat. J Hypertens. 2010;28:2227-35.

9. Geggel RL, Reid LM. The structural basis of PPHN. Clin Perinat. 1984;2:525-49.

10. Rudolph AM. High pulmonary vascular resistance after birth.I. Pathophysiologic consideration and etiologic classification. Clin Pediatr. 1980;19:585-90.

11. Rudolph AM, Yuan S. Response of the pulmonary vasculature to hypoxia and $\mathrm{H}+$ ion concentration changes. J Clin Invest. 1966:45:399-411.

12. Distefano G, Romeo MG, Parisi MG, Magro G. Physiopathologic and therapeutic aspects of the persistence of fetal circulation. Review of literature and personal histologic observations. Med Surg Ped. 1992;14:387-98.

13. Gao Y, Raj JU. Regulation of the pulmonary circulation in the fetus and newborn. Physiol Rev. 2010;90:1291-335. 
14. Ziegler JW, Ivy DD, Kinsella JP, Abman SH. The role of nitric oxide, endothelin, and prostaglandins in the transition of the pulmonary circulation. Clin Perinatol. 1995;22:387-403.

15. Steinhorn RH, Millard SL, Morinlll PC. Persistent pulmonary hypertension of the newborn. Role of nitric oxide and endothelin in pathophysiology and treatment. Clin Perinat. 1995;22:405-28.

16. Solomonson LP, Flam BR, Pendleton LC, Goodwin BL, Eichler D. The caveolar nitric oxide synthase/arginine regeneration system for $\mathrm{NO}$ production in endothelial cells. J Exp Biol. 2003;206:2083-7.

17. Deruelle P, Grover TR, Storme L, Abman SH. Effect of BAY 41-2272, a soluble guanylate cyclase activator on pulmonary vascular reactivity in the ovine fetus. Am J Physiol Lung Cell Mol Physiol. 2005;288:L727-733.

18. Jallard S, Larrue B, Deruelle P. Effects of phosphodiesterase 5 inhibitor on pulmonary vascular reactivity in the fetal lamb. Ann Thorac Surg. 2006;81:935-42.

19. Naeye RL. Arterial changes during the perinatal period. Arch Pathol. 1961;71:121-8

20. Naeye RL, Letts HV. The effects of prolonged neonatal hypoxemia on the pulmonary vascular bed and heart. Pediatrics. 1962;30:902-9.

21. Haworth SG, Reid L. Persistent fetal circulation. Newly recognized structural features. J Pediatr. 1976:88:614-20.

22. Haworth SG. Pulmonary vascular remodeling in neonatal pulmonary hypertension. Chest. 1988;93(3 Suppl):133S-8S.

23. Castilla-Fernandez Y, Copons-Fernàndez C, Jordan-Lucas R, Linde-Sillo A, Valenzuela-Palafoil I, Ferreres Pinas JC, et al. Alveolar capillary dysplasia with misalignment of pulmonary veins: concordance between pathological and molecular diagnosis. J Perinatol. 2013;33:401-3.

24. Rocha G, Baptista MJ, Guimaraes H. Persistent pulmonary hypertension of non cardiac cause in a neonatal intensive care unit. Pulmon Med. 2012;2012:818971.

25. Haworth SG. Pulmonary endothelium in the perinatal period. Pharmacol Rep. 2006;58:153-64.

26. Pearson DL, Dawling S, Walsh WF, Haines JL, Christman BW, Bazyk A. Neonatal pulmonary hypertension. Urea-cycle intermediate, nitric oxide production, and carbamoyl-phosphate synthetase function. N Engl J Med. 2001;344:1832-8.

27. Hernàndez-Diaz S, Van Marter LI, Werler MM, Loik C, Mitchell AA. Risk factors for persistent pulmonary hypertension of the newborn. Pediatrics. 2007;120:e272-282.

28. Byers HM, Dagle JM, Klein JM, Ryckman KK, MCDonald EL, Murray JC Variations in CRHR1 are associated with persistent pulmonary hypertension of the newborn. Pediatr Res. 2012;71:162-7.

29. Chandrasekar I, Eis A, Konduri GG. Betamethasone attenuates oxidant stress in endothelial cells from fetal lambs with persistent pulmonary hypertension. Pediatr Res. 2008;63:67-72.

30. da Costa DE, Nair AK, Pai MG, Al Khusaiby SM. Steroids in full term infants with respiratory failure and pulmonary hypertension due to meconium aspiration syndrome. Eur J Pediatr. 2001;160:150-3.

31. Stenmark KR, James SR, Voelkel BF. Leukotriene C4 and D4 in neonates with hypoxemia and pulmonary hypertension. N Engl J Med. 1983;309:77-80.

32. Hammerman C, Komar K, Abu-Khudair H. Hypoxic versus septic pulmonary hypertension: selective role of thromboxane mediation. Am J Dis Child. 1988;142:319-25.

33. Sanderud J, Norstein J, Saugstad OD. Reactive oxygen metabolites produce pulmonary vasoconstriction in young pigs. Pediatr Res. 1991;29:543-7.

34. Pinheiro JMB, Pitt BR, Gillis CN. Roles of platelet-activating factor and thromboxane in group B streptococcus-induced pulmonary hypertension in piglets. Pediatr Res. 1989;26:420-4.

35. Curtis J, Kim G, Wehr NB, Levine RL. Group B streptococcus, phospholipids, and pulmonary hypertension. J Perinatol. 2011;31 Suppl 1:S24-8.

36. Velvis H, Krusell J, Roman C. Leukotrienes C4, D4 in fetal lamb tracheal fluid. J Dev Physiol. 1990;14:37-41.

37. Isozaki-Fukuda Y, Kojima T, Hirata Y. Plasma immunoreactive endothelin-1 concentration in human fetal blood: its relation to asphyxia. Pediatr Res. 1991;30:244-7.

38. Fostermann U. oxidative stress in vascular disease: causes, defense mechanisms and potential therapies. Nat Clin Pract Cardiovasc Med. 2008;5:338-49.

39. Gong Y, Fediuk J, Lizotte PP, Dakshinamurti S. Hypoxic neonatal pulmonary arterial myocites are sensitized to ROS-generated 8-isoprostane. Free Radical Biol Med. 2010;48:882-94.
40. Allen KM, Haworth SG. Impaired adaptation of pulmonary circulation to extrauterine life in newborn pigs exposed to hypoxia: an ultrastructural study. J Pathol. 1986;150:205-12.

41. Kuo C, Chen J. Effect of meconium aspiration on plasma endothelin-1 level and pulmonary hemodynamics in a piglet model. Biol Neonate. 1999;76:228-34.

42. Simpson CM, Smolich JJ, Shekerdemian LS, Penny DJ. Urotensin-II contributes to pulmonary vasoconstriction in a perinatal model of persistent pulmonary hypertension of the newborn secondary to meconium aspiration syndrome. Pediatr Res. 2010;67:150-7.

43. Murphy JD, Rabinovitch M, Goldstein JD, Reid LM. The structural basis of persistent pulmonary hypertension of the newborn infant. J Pediatr. 1981;98:962-7.

44. Levin DL, Heymann MA, Kitterman JA, Gregory GA, Phibbs RH, Rudolph AM. Persistent pulmonary hypertension of the newborn infant. J Pediatr. 1976:89:626-30.

45. Turner GR, Levin DL. Prostaglandin synthesis inhibition in persistent pulmonary hypertension of the newborn. Clin Perinatol. 1984;11:581-9.

46. Gersony WM, Morishima HO, Daniel SS, Kohl S, Cohen H, Brown W, et al. The hemodynamic effects of intrauterine hypoxia: an experimental model in newborn lamb. J Pediatr. 1976:89:631-5.

47. Abman SH, Shanley PF, Accurso FJ. Failure of postnatal adaptation of the pulmonary circulation after chronic intrauterine pulmonary hypertension in fetal lambs. J Clin Invest. 1989;83:1849-58.

48. Villamor E, Le Cras TD, Horan MP, Albower AC, Tuder RM, Abman SH. Chronic intrauterine pulmonary hypertension impairs endothelial nitric oxide synthase in the ovine fetus. Am J Physiol. 1997;272:L1013-20.

49. Belik J, Keeley FW, Baldwin F, Rabinovitch M. Pulmonary hypertension and vascular remodeling in fetal sheep. Am J Physiol. 1994:266:H2303-9.

50. Delaney C, Gien J, Grover TR, Roe G, Abman SH. Pulmonary vascular effects of serotonin and selective serotonin reuptake inhibitors in the late gestation ovine fetus. Am J Physiol Lung Cell Mol Physiol. 2011;301:L937-44.

51. Kieler H, Artama M, Engeland A, Ericcson O, Furu K, Gissler M, et al. Selective serotonin reuptake inhibitors during pregnancy and risk of persistent pulmonary hypertension in the newborn:population based cohort study from the five Nordic countries. BMJ. 2012;344:d8012.

52. Jakkula M, Le Cras TD, Gebb S. Inhibition of angiogenesis decreases alveolarization in the developing rat lung. Am J Physiol Lung Cell Mol Physiol. 2000;279:L600-7.

53. Leung DW, Cacianes G, Kuang WJ, Goedel DV, Ferrara N. Vascular endothelial growth factor is a secreted angiogenic mitogen. Science. 1989:246:1306-9.

54. Grover TR, Parker TA, Zenge JP, Markham NE, Kinsella JP, Abman SH. Intrauterine hypertension decreases lung VEGF expression and VEGF inhibition causes pulmonary hypertension in the ovine fetus. Am J Physiol Lung Cell Mol Physiol. 2003;284:L508-17.

55. Gien J, Seedorf GJ, Balasubramaniam V, Markham N, Abman SH. Intrauterine pulmonary hypertension impairs angiogenesis in vitro. Role of vascular endothelial growth factor-nitric oxide signaling. Am J Respir Crit Care Med. 2007;176:1146-53.

56. Sheata SM, Sharma HS, Mooi WJ, Tibboel D. Pulmonary Hypertension in human newborns with congenital diaphragmatic hernia is associated with decreased vascular expression of nitric oxide synthase. Cell Biochem Biophys. 2006;44:147-55.

57. Keller RL, Tacy TA, Hendricks-Munoz K, Xu J, Moon-Grady AJ, Neuhaus J, et al. Congenital diaphragmatic hernia:endothelin-1, pulmonary hypertension, and disease severity. Am J Respir Crit Care Med. 2010;182:555-61.

58. Luna MS, Franco ML, Bernardo B. Therapeutic strategies in pulmonary hypertension of the newborn: where are we now? Curr Med Chem. 2012:19:4640-53.

59. Lazar DA, Cass DL, Olutoye OO, Welty SE, Fernandes CJ, Rycus PT, et al. The use of ECMO for persistent pulmonary hypertension of the newborn: a decade of experience. J Surg Res. 2012;177:263-7.

60. Kulik TJ, Lock JE. Pulmonary vasodilator therapy in persistent pulmonary hypertension of the newborn. Clin Perinatol. 1984;11:693-701.

61. Roberts JD, Shaul PW. Advances in the treatment of persistent pulmonary hypertension of the newborn. Pediatr Clin N AM. 1993;40:983-1004

62. Geggel RL. Inhalational nitric oxide: a selective pulmonary vasodilator for treatment of persistent pulmonary hypertension of the newborn. J Pediatr. 1993;123:76-9. 
63. Konduri GG, Kim UO. Advances in the diagnosis and management of persistent pulmonary hypertension of the newborn. Pediatr Clin N Am. 2009;56:579-600.

64. Christou H, Van Marter LJ, Wessel DL, Allred EN, Kane JW, Thompson JE, et al. Inhaled nitric oxide reduces the need for extracorporeal membrane oxygenation in infants with persistent pulmonary hypertension of the newborn. Crit Care Med. 2000;28:3722-7.

65. The Neonatal Inhaled Nitric Oxide Study Group. Inhaled nitric oxide in full-term and near full-term infants with hypoxic respiratory failure. N Engl J Med. 1997:336:597-604.

66. Gonzàlez A, Fabres J, D'Apremont I, Urcelay G, Avaca M, Gandolfi C, et al. Randomized controlled trial of early compared with delayed use of inhaled nitric oxide in newborns with a moderate respiratory failure and pulmonary hypertension. J Perinatol. 2010;30:420-4.

67. Finer NN, Barrington KJ. Nitric oxide for respiratory failure in infants born at or near term. Cochrane Database Syst Rev. 2006;4:CD000399.

68. Steinhorm RH, Russel JA, Morin FC. Disruption of cyclic GMP production in pulmonary arteries isolated from fetal lambs with pulmonary hypertension. Am J Physiol Heart Circ Physiol. 1995;268:H1483-9.

69. Baquero H, Soliz A, Neira F, Venegas ME, Sola A. Oral sildenafil in infants with persistent pulmonary hypertension of the newborn: a pilot randomized blinded study. Pediatrics. 2006;117:1077-83.

70. Vargas-Origel A, Gòmez-Rodriguez G, Aldana-Valenzuela C, Vela-Huerta MM, Amador-Licona N. The use of sildenafil in persistent pulmonary hypertension of the newborn. Am J Perinatol. 2010;27:225-30.

71. Steinhorm RH, Kinsella JP, Pierce C, Butrous G, Dilleen M, Oakes M, et al. Intravenous sildenafil in the treatment of neonates with persistent pulmonary hypertension. J Pediatr. 2009;155:841-7.

72. Noori S, Friedlich P, Wong P, Garingo A, Seri I. Cardiovascular effects of sildenafil in neonates and infants with congenital diaphragmatic hernia and pulmonary hypertension. Neonatology. 2007;91:92-100.

73. Mohamed WA, Ismail M. A randomized, double-blind, placebo-controlled, prospective study of bosentan for the treatment of persistent pulmonary hypertension of the newborn. J Perinatol. 2012;32:608-13.

74. Wedgwood S, Dettman RW, Black SM. ET-1 stimulates pulmonary arterial smooth muscle cell proliferation via induction of reactive oxygen species. Am J Physiol. 2001;281:L1058-67.

75. Wedgwood S, Black SM. Role of reactive oxygen species in vascular remodeling associated with pulmonary hypertension. Antioxid Redox Signal. 2003:5:759-69.

76. Wedgwood S, Black SM. Molecular mechanisms of nitric oxide-induced growth arrest and apoptosis in fetal pulmonary arterial smooth muscle cells. Nitric Oxide. 2003;9:201-10.

77. Brennan LA, Steinhorm RH, Wedgewood S, Mata-Greenwood E, Roark EA, Russel A, et al. Increased superoxide generation is associated with pulmonary hypertension in fetal lambs: a role for NADPH oxidase. Circ Res. 2003;92:683-91.

78. Black SM, Johengen MJ, Soifer SJ. Coordinated regulation of genes of the nitric oxide and endothelin pathways during the development of pulmonary hypertension in fetal lambs. Pediatr Res. 1998:44:821-30.

79. Ananthakrishnan M, Barr FE, Summar ML, Smith HA, Kaplowitz M, Cunningham G, et al. L-Citrulline ameliorates chronic hypoxia-induced pulmonary hypertension in newborn piglets. Am J Physiol Lung Cell Mol Physiol. 2009;297:L506-511

80. Smith HAB, Canter JA, Christian KG, Drinkwater DC, Scholl FG, Christman BW, et al. Nitric oxide precursors and congenital heart surgery: a randomized controlled trial of oral citrullin. J Thorac Cardiovasc Surg. 2006;132:58-65.

81. Shifren JL, Doldi N, Ferrara N, Mesiano S, Jaffe RB: In the human fetus, vascular endothelial growth factor is expressed in epithelial cells and miocytes, but not in vascular endothelium: implications for mode of action. J Clin Endocrinol Metab 79:316-322

82. Papapetropoulos A, Garcia-Cardena G, Madri JA, Sessa WC. Nitric oxide production contributed to angiogenic properties of vascular endothelial growth factor in human endothelial cells. J Clin Invest. 1997;100:3131-9.

83. Chang R, Andreoli S, Ng YS, Truong T, Sith SR, Wilson J. VEGF expression is downregulated in nitrofen-induced congenital diaphragmatic hernia. J Pediatr Surg. 2004;39:825-8.

84. Shaul PW, Yuhanna IS, German Z, Chen Z, Steinhorm RH, Morin FC. Pulmonary endothelial NO synthase gene expression is decreased in fetal lambs with pulmonary hypertension. Physiol Lung Cell Mol Physiol. 1997;16:L1005-12.
85. Fike CD, Kaplowitz MR, Thomas CJ, Nelin LD. Chronic hypoxia decreases nitric oxide production and endothelial nitric oxide synthase in newborn ping lungs. Am J Physiol Lung Cell Mol Physiol. 1998;274:L517-26.

86. Teng RJ, Du J, Xu H, Bakhutashvili I, Eis A, Shi Y, et al. Sepiapterin improves angiogenesis of pulmonary artery endothelial cells with in utero pulmonary hypertension by recoupling endothelial nitric oxide synthase. Am J Physiol Lung Cell Mol Physiol. 2011;301:L334-45.

87. Teng RJ, Eis A, Bakhutashvili I, Arul NKonduri GG. Increased superoxide production contributes to the impaired angiogenesis of fetal pulmonary arteries with in utero pulmonary hypertension. Am J Physiol Cell Mol PHysiol. 2009;297:L184-95.

88. Tuder RM, Abman SH, Braun T, Capron F, Stevens T, Thistlethwaite A, et al. Development and pathology of pulmonary hypertension. J Am Coll Cardiol. 2009;54(N 1,suppl S):S3-9.

89. Alphonse RS, Thèbaud B. Growth factors, stem cells and bronchopulmonary dysplasia. Neonatology. 2011;99:326-37.

90. Hansmann G, Fernandez-Gonzalez A, Aslam M, Vitali SH, Martin T, Mitsialis SA, et al. Mesenchymal stem cell-mediated reversal of bronchopulmonary dysplasia and associated pulmonary hypertension. Pulm Circ. 2012;2:170-81.

91. Alphonse R, Vadivel A, Waszac P, Fung M, Coltan L, Eaton FYoder M, et al. Existence, functional impairment and therapeutic potential of endothelial colony forming cells (ECFCs) in oxygen-induced arrested alveolar growth. Am J Respir Crit Care Med. 2011;183:A1237.

92. Fung ME, Thèbaud B: Stem cell-based therapy for neonatal lung disease. It is in the juice. Pediatr Res 2013, doi:10.1038/pr2013.176

93. O'Reilly $M$, Thèbaud $B$. The promise of stem cells in bronchopulmonary dysplasia. Sem Perinatol. 2013;37:79-84.

94. Lee C, Mitsialis SA, Aslam M, Vitali SH, Vergadi E, Kostantinou G, et al. Exosomes mediate the cytoprotective action of mesenchymal stromal cells on hypoxia-induced pulmonary hypertension. Circulation. 2012;126:2601-11.

\section{Submit your next manuscript to BioMed Central and take full advantage of:}

- Convenient online submission

- Thorough peer review

- No space constraints or color figure charges

- Immediate publication on acceptance

- Inclusion in PubMed, CAS, Scopus and Google Scholar

- Research which is freely available for redistribution 